\title{
Death Anxiety, Religiosity and Culture: Implications for Therapeutic Process and Future Research
}

\author{
Apurva-kumar Pandya ${ }^{1, *(1)}$ and Tripti Kathuria ${ }^{2}$ \\ 1 Regional Resource Center for Health Technology Assessment, Indian Institute of Public Health, \\ Gandhinagar 382042, Gujarat, India \\ 2 Independent Researcher, Meerut 250002, Uttar Pradesh, India; triptikathuria@gmail.com \\ * Correspondence: apandya@iiphg.org
}

check for updates

Citation: Pandya, Apurva-kumar, and Tripti Kathuria. 2021. Death Anxiety, Religiosity and Culture: Implications for Therapeutic Process and Future Research. Religions 12: 61 https://doi.org/10.3390/rel12010061

Received: 9 November 2020

Accepted: 5 January 2021

Published: 16 January 2021

Publisher's Note: MDPI stays neutral with regard to jurisdictional clai$\mathrm{ms}$ in published maps and institutional affiliations.

Copyright: (C) 2021 by the authors. Licensee MDPI, Basel, Switzerland. This article is an open access article distributed under the terms and conditions of the Creative Commons Attribution (CC BY) license (https:// creativecommons.org/licenses/by/ $4.0 /)$.
Abstract: Death anxiety is a common phenomenon that humans experience. It is multidimensional. There has been an upsurged interest around the discussion on death anxiety across the globe, however, much of the literature focuses on the concept of death anxiety, religiosity, and its role in mental health conditions. Further, studies on death anxiety are scattered and at times disconnected. It is important to review existing literature to get an overview of the current direction in research and understand its relevance to facilitate therapeutic processes. In this scoping review, literature was searched in databases such as PubMed, Scopus, and PsychINFO using key words such as "death anxiety", "fear of death", religion", "culture", and "psychopathology" combined with Boolean operators to narrow down the search results. The initial search yielded 614 records, of which 546 records were removed based on title review (363), abstract review (94), and full-text review (89). Finally, 68 articles were appraised, narratively synthesized, and thematically presented. Major themes revealed in the literature were theoretical frameworks of death anxiety, religiosity, universality, psychological effects of death anxiety, psychopathology, and religious coping strategies. There is a need to assess client's death anxiety and address them using religious rituals and coping mechanisms.

Keywords: death anxiety; religiosity; universality; coping skills

\section{Introduction}

Death anxiety is an unavoidable common phenomenon in our lives across cultures and religions. It is multidimensional and explained by different theoretical frameworks. Death is an inevitable experience that generates a reduced sense of safety and stronger fear (Alkozei et al. 2019). There has been an increased interest on the discussion of death anxiety across the globe, however, much of the literature focuses on the concept of death anxiety, religiosity, and its role in mental health conditions. Furthermore, studies on death anxiety are scattered and at times disconnected. It restricts unified understanding of death anxiety and guides developing therapeutic intervention. It is indeed important to review existing literature to understand the current direction in research and its relevance to facilitate therapeutic process.

This paper reviews theoretical frameworks of death anxiety, religiosity, and cultural variation in the concept of death anxiety. Moreover, psychological effects of death anxiety, underlying mechanisms of mental health conditions, and religious coping strategies are highlighted. In the end, implications for therapeutic practice and research are presented.

\section{Materials and Methods}

The study adopted a scoping review approach (Arksey and O'Malley 2005) to identify relevant published literature on the death anxiety, religiosity, universality, psychological effects, and mental health, and religious rituals to ease death anxiety. 


\subsection{Search Strategy and Selection Criteria}

Published literature was searched in databases such as PubMed, Scopus, and PsychINFO. The key words, "death anxiety", "fear of death", "religion", "culture", and "psychopathology" were used. These key words were combined with Boolean operators to narrow down the search results. No restrictions of time were applied in the literature search. Records that were relevant to defined themes, records in English, published in peer-reviewed and indexed journals were included in the review. Records were excluded if they were duplicates, letter to editor, editorials, non-peer reviewed articles, without access to full-texts, or published in other than English language.

The initial search yielded 614 records (PubMed 165; PsychINFO 129; Scopus 320) of which, 363 were excluded based on title review and duplications. Later, 94 records were rejected based on abstract review considering their relevance to the defined themes and types of studies such as letter to editor and academic thesis. Finally, 157 full texts were selected for review, of which a total 68 records were included in the study. The PRISMA diagram is presented in Figure 1.

Total records identified

(PubMed=165; PsychINFO=129; Scopus=320)

$(\mathrm{n}=614)$

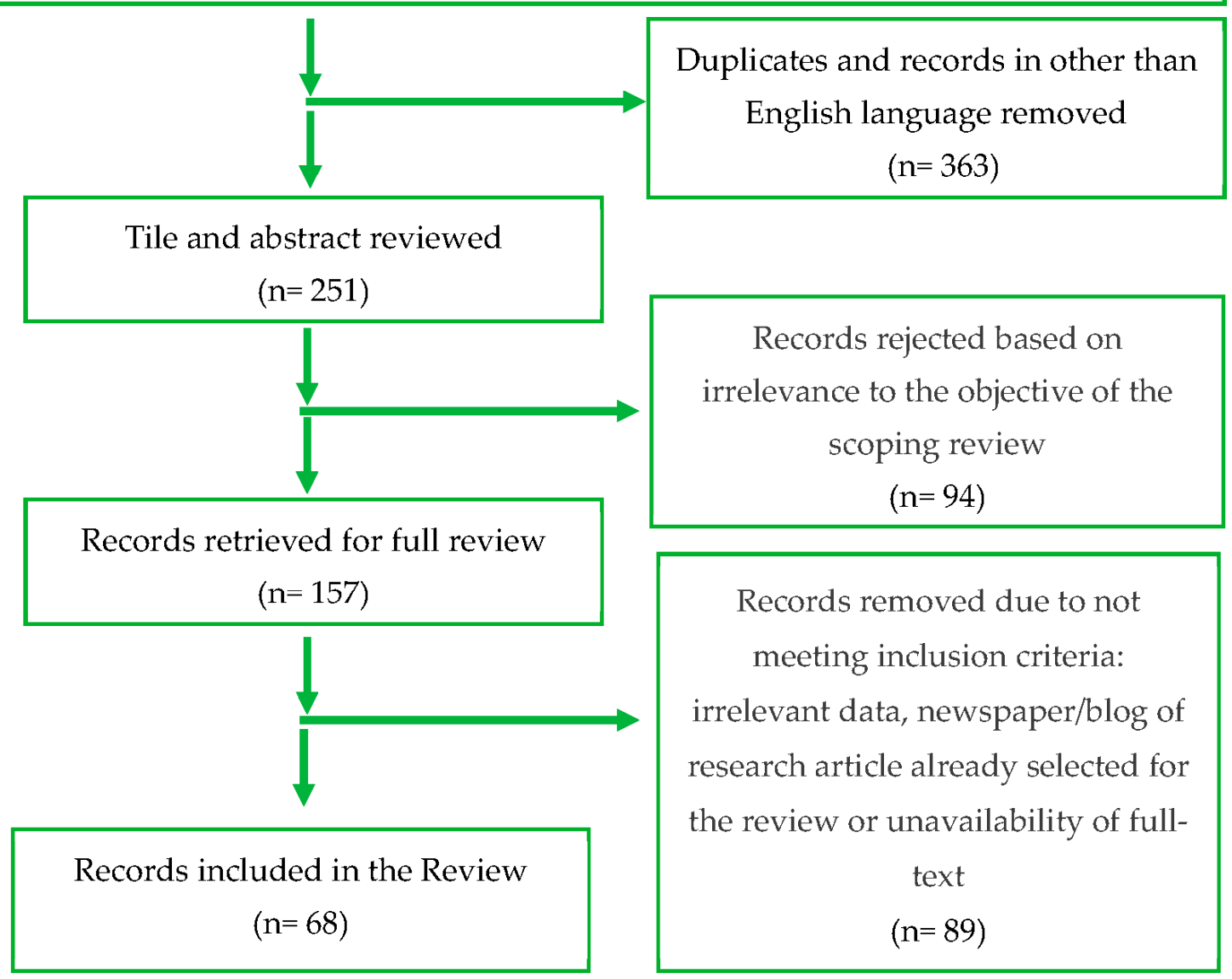

Figure 1. PRISMA diagram of the study.

\subsection{Data Extraction and Synthesis}

The literature search was done separately by two researchers. Initially, records were searched by the first author (A.P.). The results were matched by repeating search exercises by the second author (T.K.) using keywords, who removed duplicating and unqualified 
records based on the exclusion criteria. Selected records were coded in the domains such as author's name, year of publication, type of publication, country, definition of death anxiety, theoretical framework of death anxiety, religiosity and cultural variation, gaps in the literature, and recommendations. The full text of selected records was carefully reviewed. Data extraction was reviewed by T.K. Discrepancies in the data presentation were resolved by discussion and agreements between authors.

\subsection{Data Synthesis}

We had adapted a thematic approach which drew on the principles of meta-synthesis for analyzing and synthesizing the data (Lachal et al. 2017). We have followed seven key steps of meta-synthesis (Britten et al. 2002): (i) Getting started, (ii) deciding what is relevant to the initial interest, (iii) reading the studies, (iv) determining how the studies are related, (v) translating the studies into comprehensible description, (vi) synthesizing translations, (vii) and expressing the synthesis. These steps were used to derive interpretations from the information gathered from selected studies. Overall data synthesis was reviewed by both authors, and evidence was narratively synthesized and thematically presented.

\section{Results and Discussion}

As its name reflects, death anxiety has been defined as a sense of apprehension, or fear, at the thought of death or anything to do with the process of dying (Lehto and Stein 2009). Belsky (1999) has defined death anxiety as the thoughts, fears, and emotions about the ultimate event of life. Some key definitions of death anxiety are presented in Table 1.

Table 1. Some definitions of death anxiety.

\begin{tabular}{cc}
\hline Tomer and Eliason (1996) & $\begin{array}{r}\text { Death anxiety could be "a negative emotional reaction fueled by the anticipation of a state } \\
\text { of mind in which the self doesn't exist". (p. 345) }\end{array}$ \\
\hline Farley (2004) & $\begin{array}{r}\text { Death anxiety is a feeling of dread, apprehension or solicitude (anxiety) when one thinks } \\
\text { of the process of dying, or ceasing to "be". (p. 73) }\end{array}$ \\
\hline Malinauskaite et al. (2017) & $\begin{array}{r}\text { Death anxiety may be "a feeling of unsafety or fear related to death, [which is] ... often } \\
\text { accompanied with avoidance-focused coping strategies". (p. 6) }\end{array}$ \\
\hline Dadfar and Lester (2017) & "Death anxiety is a fear of death of oneself as well as fear of death of others". (p. 1061) \\
\hline
\end{tabular}

Death anxiety is universal, present in all societies; however, the experience of death anxiety may vary depending on religiosity, gender, psychological state, and age (Chan and Yap 2009; Dadfar et al. 2016; Dadfar and Lester 2020; Lehto and Stein 2009; Madnawat and Kachhawa 2007). As death anxiety is a common human experience, relieving death anxiety may play a vital role in improving quality of life (Zhang et al. 2019).

\subsection{Types of Death Anxieties}

Death anxiety is caused by the fear of pain and also the unknown, of separation from the loved ones and permanent end of existence after death. Langs (2004) has classified three forms of death anxiety: (1) Predatory death anxiety (triggered by external situations that may be physically or psychologically dangerous, and anxiety ensures the survival of the organism in the face of adversities); (2) predator death anxiety (results from an individual harming someone either physically or mentally, which is often accompanied by unconscious guilt that may compel an individual to punish oneself); and (3) existential death anxiety (emanates from the knowledge that life has an end and distinguish self from others. Usually individuals defend against death anxiety through denial, and excess use of denial tends to be detrimental). A few research scholars have discerned four types of death anxiety, namely, personal death anxiety, personal dying anxiety, anxiety toward the death of someone close, and anxiety toward the death of someone close (Lester 1994; Michael and Snyder 2005). 


\subsection{Theories on Death Anxiety}

Several theoretical models relevant to the study of death anxiety have appeared in the literature. Leading theories about death anxiety were developed by Sigmund Freud (Thanatophobia), Ernest Becker (Terror Management Theory), Erik Erikson (Wisdom: Ego integrity vs. despair) and Kastenbaum (Edge theory).

Thanatophobia is fear of death. Sigmund Freud was the first theorist to coin death anxiety and hypothesized that individuals express a fear of death as a response to cope with unresolved childhood conflicts. Thanatophobia is evolved from the Greek mythological figure of death, Thanatos. Ernest Becker proposed terror management theory supported existential views which turned death anxiety theories towards a new dimension. Death anxiety can generate fears of existence such as fear of being alone. Many try to deny death and to keep their anxiety under strict regulation resulting in mortality salience, i.e., become responsive to the understanding of certainty of death and instinctively try to suppress it in response to fear. This method of suppression usually links towards cultural, spiritual, and religious beliefs, and seeks external support. Erik Erikson formulated the psychosocial theory which envelops the concept that once an individual reaches the latest stages of life, they reach "ego integrity" - a state when one comes to terms with their life and accepts it when one finds meaning or purpose in their life. On the contrary, when individual views their life as a series of failed and missed opportunities, then they do not reach the ego integrity stage and exhibit death anxiety. This stage is known as Wisdom: Ego integrity vs. despair. Kastenbaum's Edge theory postulates that death anxiety contains a survival function that evolves in perceived life-threatening situations.

Hoelter and Hoelter (1978) conceptualized death anxiety as a multidimensional concept and offered eight elements of death anxiety: (1) Fear of dying process, (2) fear of premature death, (3) fear of death of significant others, (4) phobic fear of death, (5) fear of being destroyed, (6) fear of the body after death, (7) fear of the unknown, and (8) fear of the dead. Similarly, Florian and Mikulincer (1998) have articulated three mechanisms of death anxiety: Intrapersonal, interpersonal, and transpersonal. The intrapersonal component focuses on the impact death has on one's body and psyche. Fear of losing the body after death is prominent during this phase. An interpersonal component brings attention to how interpersonal relationships get stricken by death and therefore the transpersonal component, on the opposite hand, is said with fears about the afterlife.

Wong (2008) developed the meaning management theory. It highlights that human reactions to death are complex, multifaceted, and dynamic. The theory proposes three types of death acceptances as Neutral, Approach, and Escape acceptances. Besides these, it explains different aspects of the meaning of death that eventually regulates death anxiety include finality, uncertainty, annihilation, ultimate loss, disruption of life flow, leaving the loved ones, intense pain, sense of loneliness, prematurity of death, failure of life, unfulfilled work, judgment, and retribution. The theory indicates our existence is based on two primary motivations: To survive and to find meaning and reason for survival. The pursuit of meaning in life can be the best remedy to allay death anxiety. In other words, individuals who find meaning in their existence and contribute productively to the society may not feel threatened by inevitable death (Juhl et al. 2010).

Other theories include self-realization theories (Neimeyer and Chapman 1980; Rogers 1980), personal construct theory (Kelly 1955), an illusion of control theory (Taylor and Brown 1988; Taylor et al. 1989), self-concept discrepancy theory (Higgins 1987), search-formeaning theories (Antonowski 1979; Frankl 1963; Maddi 1970; Taylor 1983), theories of denial (Becker 1973), and a two-factor theory of death (Gilliland and Templer 1986; Lonetto and Templer 1986; Templer 1976).

Hossain and Gilbert (2010) postulated Death and Adjustment Hypotheses (Hossain and Gilbert 2010). It postulated two things; first, death should not be considered the end of existence, second, the belief that the immortal pattern of human existence can only be adopted in an exceedingly morally rich life with the attitude towards morality and materialism balanced mutually. 
The recurrent four themes in these theories are death as self-defeating, radical transformation, a threat to the purpose of life, and a threat to the realization of life potential. Such diversity in theoretical approaches has led to varied perspectives on death anxiety; however, these theories have substantial overlapping concepts (Barnett et al. 2018). It means threats to death anxiety can be classified based on two factors: External causes, such as presence and search for meaning in life; and the internal evaluation of the self (Florian and Mikulincer 1998).

\subsection{Religiosity and Death Anxiety}

Many empirical studies have attempted to test whether death anxiety and religiosity are related. Allport and Ross (1967) highlighted mutually exclusive dimensions of religiosity: Intrinsic religiosity and extrinsic religiosity. Intrinsic religiosity refers to the people who live their religion with sincerity, whereas people with high extrinsic religiosity consider religion as a means to comfort, console, and social connections (Allport and Ross 1967). This stance is supported by numerous studies, for example, people with higher intrinsic religiosity expressed lower death anxiety compared to people with high extrinsic religiosity (Ardelt and Koenig 2006; Arrowood et al. 2018; Cohen et al. 2005; Hui and Fung 2008).

Templer (1972) and Kahoe and Dunn (1975) have reported that the more religiously committed persons have lower death anxiety than the less committed. However, Sullivan (1977) did not find support for this conclusion. In a meta-analysis of intrinsic and extrinsic religiousness, Donahue (1985) described several studies that examined the relationship between religiosity and death anxiety and studies reported mixed findings which were seconded by literature review conducted by Donovan (1994). An Indian study indicated that although Muslim subjects were more anxious than Christian and Hindu, the degree of commitment to one's religious practices and beliefs did not intensify or reduce death anxiety (Mahabeer and Bhana 1984). The inconclusiveness of religiosity and death anxieties continue even in present scholarship. A review of studies in the last decade highlights that some studies highlighted positive correlations (Saleem and Saleem 2020), few indicated negative correlations (Marin 2019), whereas the rest of the studies presented with insignificant correlations (Bakan et al. 2019). For example, a review of studies led by Ellis et al. (2013) provided inconclusive findings. They reviewed 84 papers, and of these, 40 showed a negative correlation between death anxiety and religiosity, 27 showed a positive correlation, while 41 showed no significant correlation in either direction (Ellis et al. 2013). They found null effects of age or gender on religiosity, but revealed that the negative correlations were driven by samples that skewed religiously, for instance, about $42 \%$ of these studies had included only individuals who were moderately and strongly religious. A recent systematic review conducted by Jong and colleagues in 2018 reviewed 100 studies. They found that death anxiety theories of religion generally predict an inverted-U relationship between death anxiety and religiosity, specified death anxiety was reported lowest among very non-religious as well as very religious individuals and was recorded highest among their counterparts. On a closer examination of studies that directly tested for curvilinearity (10 out of 11 studies), it has lent some support for the existence of an inverted-U pattern (Jong et al. 2018). Contrarily, Abdel-Khalek and Lester (2009) did not find a correlation between religiosity and death anxiety. Most recent studies, however, found lower death anxiety in people with strong religious views and greater in people with lenient religious beliefs (Wen 2010).

\subsection{Cultural Variation in Death Anxiety}

Research comparing death anxiety across cultures generally found in non-Indian samples and surprisingly, the findings of these studies were indicative of higher death anxiety than eastern samples (Ens and Bond 2007; Lester et al. 2007; Li et al. 2017; Park et al. 2012). This indicates cultural variation in death anxiety. 


\subsection{Universality of Death Anxiety}

Is death anxiety universal? Lehto and Stein (2009) believe so, arguing that encountering death and the anxiety generated by knowing the fact that death is inevitable is a universal psychological response. However, there's no consensus among scholars about whether death anxiety is universal or specific to religions and/or cultures. Evidence indicates a mixed or inconclusive response. Leming and Dickinson (2000) noted death anxiety is expressed through a variety of death-related practices and rituals and categorically concluded that not all cultures fear death. Further, Moore and Williamson (2003) marked that fear of death is not instinctive, but rather learned. Kalish (1985) has pointed out three ways of developing death anxiety as follow:

(a) Early socialization: Death anxiety is constantly reinforced during early childhood. As a child interacts with the environment during early socialization, the child learns about dangers and its consequences to keep themselves safe and away from danger. Fear of death is, therefore, learned and reinforced as a consequence of a dangerous or life-threatening situation.

(b) Separation: Separation from mother or the significant other generates anxiety which is known as separation anxiety. The temporary separations are painful for the infants leaving them feeling helpless. Such brief separations have an additive effect on the infant and learn to believe death as the permanent separation. The anticipated pain of this permanent separation leads to anxiety.

(c) Entering the unknown: Fear of death also develops because death is an unknown arena. The mysterious character of death creates anxiety as none knows about it.

\subsection{Psychological Effects of Death Anxiety}

Researches indicate that people tend to become increasingly defensive in ways that are harmful to themselves as well as to others when death anxiety is aroused. Although people may initially embrace life more fully, over time, most people shift to a more defended action. However, as we discussed in an earlier section, these reactions vary across religiosity, age, and gender. People with death anxiety deny death to protect themselves and fail to value other relevant and meaningful influences by giving importance to insignificant issues in their lives.

In one experiment conducted by Solomon and colleagues (2015), subjects (judges) were subliminally presented with the word "death". After these subjects strongly endorsed the worldview of their own ethnic group or nation while, at the same time, they denigrated members of other groups whose worldviews differed from their own (Solomon et al. 2015). It means that judges who were exposed to the word "death" exercised more punitive sentences than those in the control group who were not exposed. If the single word "death" introduced in an experimental setting can produce significant changes in subjects' attitudes and actions, one can imagine the powerful effect of the word "death" in countless situations in the real world on attitude and actions.

As researches indicate a belief in religion represents the denial of death. Some individuals rationalize death, taking a more philosophical position to keep themselves away from feeling about their own mortality (Kastenbaum 2000). Others may believe that someone will ultimately save them - a relationship partner, a guru, or other (Kastenbaum 2000). Some defenses against death anxiety have beneficial side effects; for example, the symbolic immortality, finding lasting meaning in devotion to family, friends, and people at large, and attempting to leave a positive legacy generally has a good effect. Other defenses, such as living on through one's children, have a generally negative effect (Hart and Goldenberg 2008).

\subsection{Death Anxiety and Mental Health Conditions}

Previous research has identified a connection between death anxiety, quality of life, and a range of mental health conditions (Galek et al. 2007; Sherman et al. 2010; Bahrami et al. 2013; Iverach et al. 2014; Willis et al. 2019). A recent study indicated death anxiety as a predictor of mental health conditions (Menzies et al. 2019) and numerous studies have 
demonstrated symptomatology of various disorders, including anxiety disorders, posttraumatic stress disorder, obsessive-compulsive disorder, depression, and eating disorders (Iverach et al. 2014; Le Marne and Harris 2016; Menzies and Dar-Nimrod 2017; Ongider and Eyuboglu 2013).

A few studies have explored the causal role of death anxiety in mental illnesses. These studies have revealed that death anxiety increases avoidance of stimuli that generates fear among phobics, social avoidance and attentional biases towards threats among the socially anxious, and even restricted consumption of high caloric foods amongst women, suggesting the relevance of death anxiety in eating disorders (Finch et al. 2016; Strachan et al. 2007; Iverach et al. 2014). One study examined the effect of mortality salience on compulsive handwashing in a large sample of individuals diagnosed with obsessivecompulsive disorders (Menzies and Dar-Nimrod 2017). In another recent study, participants with a panic disorder or a somatic symptom-related disorder were shown increased time checking one's body for physical symptoms, increased perceived threat of one's symptoms, and also increased intention to visit a medical specialist in the near future (Menzies and Menzies 2020). Therefore, these findings establish that death anxiety cause anxious behavior for those vulnerable to health-related worries (Menzies and Menzies 2020).

\subsection{Religious Coping with Death Anxiety}

Studies have shown that many individuals regard religion as a source of coping with the difficult moments of their lives (Mohammadzadeh and Najafi 2020; Koenig 2012; Willis et al. 2019). Death anxiety is often accompanied by the experience of fear, sadness, and anger, and individuals attempt to find a way to cope with them. Nevertheless, talking about death anxiety may be difficult or largely unavailable, as this topic is considered taboo and the only way left with them is to link these with religious beliefs and rituals. Religions provide a platform to expand individuals' self-awareness, address existential crises of life and death, contemplate the mystery of existence, and face their emotional pain. Religious explorations generally believe they are developing a deeper and more respectful view of themselves, as well as becoming empathetic to other people's feelings and well-being. These sentiments are often translated into kindness and compassion toward other people. When individuals challenge their defensive reactions to death anxiety, they are encouraged to confront death with equanimity, live in the present, and experience both the joy and pain of existence without resorting to illusion. Although greater religious participation is not a guaranteed remedy of death anxiety, Alvarado argued that strong religious conviction and belief in an afterlife could reduce death anxiety (Alvarado et al. 1995). In fact, religious faith, spiritual belief, and life satisfaction decrease death anxiety and act as a preventive factor against feelings of existential despair (Lewis 2014; Mohammadzadeh and Najafi 2020). A number of studies indicate the role of spiritual experiences and life satisfaction as a coping mechanism (Moore 2013; Saini et al. 2016; Taghiabadi et al. 2017). Furthermore, social detachment was demonstrated as an important religious coping practice for managing death anxiety (Maheshwari and Mukherjee 2019). Spiritual practices such as a daily schedule of yoga and meditation were found to be effective in relieving symptoms of depression and anxiety (Bridges and Sharma 2017; Varambally and Gangadhar 2020), which may provide great relief from death anxiety as well.

\section{Discussion}

Most reviewed literature was from western countries, and evidence on this topic is restricted in the South Asian context. Thus, researches in this area are warranted. The multidimensional nature of death anxiety and religiosity is complex and hence is not sufficiently addressed in research (Harding et al. 2005). A multidimensional concept of religiosity should be translated into research on death anxiety.

Limited cross-cultural researchers studied the impact of cultures on death anxiety (Li et al. 2017), yet these studies ignored the possible factors underlying the process between different cultures and death anxiety. Looking at the underlying mechanism of 
cross-cultural differences in death anxiety could help mental health practitioners to understand death anxiety in a diverse population. Therefore, psychologists and other social scientists should prioritize multinational studies on death anxiety.

Limited understanding exists on the effect of coping responses to avert negative psychological consequences. The potential role of religious rituals in easing negative psychological effects and addressing mental illnesses remain unknown. Many studies suggest that fear of death is a transdiagnostic construct-an underlying process or a cause in psychopathology (American Psychiatric Association 2013; Iverach et al. 2014; Menzies et al. 2019); however, for better understanding of death anxiety, research with clinical samples is warranted. When death anxiety is believed to be an underlying condition for numerous mental disorders, there are possibilities that death anxieties are not targeted for treating existing diagnosis and death anxiety as such remains untreated, which may cause other psychopathological conditions. This is as often considered as a 'revolving door' phenomenon (Iverach et al. 2014, p. 590). As recommended by Menzies and Menzies (2020), death anxiety needs to be assessed and explicitly included in treatment so as to ameliorate root causes of mental disorders and foster client 's overall wellbeing.

The role of religious and spiritual interventions has been found promising, especially dealing with chronic and terminal illnesses, trauma, relationship issues, and mental illness such as schizophrenia (Ross et al. 2015). However, studies have not reported religious and spiritual interventions for addressing death anxiety. Hodge (2013) highlighted the importance of assessing spirituality and religion in routine assessment of clients for comprehensive understanding of a client, even if issues around spirituality and religions are not a focus of therapy. Dein (2013) argued that the consideration of spiritual and religious practices is essential part of psychotherapy for depression and anxiety, as meaning of life and control in life are significantly affected in both disorders. Serious health problems, grief, loss, and relationship conflict, struggles for meaning, or experiences that trigger doubt in one's worldview, may also require direct consideration of religious and spiritual issues in therapeutic process (Pargament and Saunders 2007; Pargament et al. 2014; Sperry 2012). Thus, in the role of assessment of death anxiety, spiritual and religious beliefs and practices are promising for alleviating death anxiety or reducing the severity of mental illnesses where death anxiety is an underlying mechanism. Although spirituality and religious issues are acknowledged for facilitating therapeutic processes, a systematic review revealed that religious issues are neglected within current training programs (Jafari 2016). The need to introduce assessment of death anxiety, and spiritual and religious beliefs and practices in the academic curriculum of psychiatry, clinical psychology, and counselling is obvious.

\subsection{Implications for Therapeutic Process}

As death anxiety is often an underlying cause for many mental conditions, mental health professionals should assess underlying death anxiety and facilitate dealing with death anxiety during therapeutic sessions. If death anxiety is not addressed, psychopathology may continue or relapse or manifest in different mental illnesses (Menzies et al. 2018). Thus, mental health professionals need orientation on assessing underlying mechanisms of death anxiety, appreciate the religious and cultural beliefs and rituals related to death and utilize personal, religious, and spiritual resources of clients to deal with death anxiety. Spiritual and religious interventions targeted to address death anxieties can be applied in various group counselling and therapy settings such as psychoeducational groups, group psychotherapeutic group, and twelve step groups (Cornish and Wade 2010; Viftrup et al. 2013). A competency-based model designed by Maximo (2019) can be used to enhance counsellor/clinician competencies by enhancing sensitivity to spiritual and religious sentiments, which allows greater responsiveness to the clients' needs, values, and preferences.

It would be worthy of learning current counselling practices in dealing with death anxiety. The community of practice (COP) approach (where practitioners come together and collectively share and learn on a common platform on a regular basis) can be instrumental 
in collaborating with counselling practitioners as well as mental health professionals for documenting their practices on this topic.

\subsection{Implications for Prospective Research}

Present studies have identified a connection between death anxiety, quality of life, and a range of mental health conditions; however, interventional studies in the South Asian cultural context are restricted. Death anxiety is a transdiagnostic construct; hence, future research can assess how psychotherapists, counsellors, and clinicians deal with death anxiety among people living with mental illness in different cultural contexts. Further, concerns related to identifying death anxiety as an area for intervention requires deliberation and consensus across mental health professionals. Besides these, the use of religion and spirituality within counselling practice for reducing death anxiety is not adequately explored by researchers. Formulating a consortium on death studies for South Asia can be instrumental in promoting research on this topic and updating counselling and clinical practice around the same. Future studies need to assess effectiveness of spiritual and religious interventions in alleviating death anxiety or reduce severity of mental illness where death anxiety is an underlying causal factor.

Author Contributions: Conceptualization, A.-k.P.; methodology, T.K. and A.-k.P.; formal analysis, A.-k.P.; data curation, T.K. and A.-k.P.; writing—original draft preparation, A.-k.P.; writingReview and editing, T.K. and A.-k.P. All authors have read and agreed to the published version of the manuscript.

Funding: This research received no external funding.

Institutional Review Board Statement: Not applicable.

Informed Consent Statement: Not applicable.

Data Availability Statement: No primary data were created or analyzed in this study. Data sharing is not applicable to this article.

Conflicts of Interest: The authors declare no conflict of interest.

Ethical Approval Statement: The study was based on secondary literature which did not involve primary data collection. Thus, ethical approval was exempted.

\section{References}

Abdel-Khalek, Ahmed M., and David Lester. 2009. Religiosity and death anxiety: No association in Kuwait. Psychological Reports 104: 770-22. [CrossRef] [PubMed]

Alkozei, Anna, Ryan Smith, Lauren A. Demers, Mareen Weber, Sarah M. Berryhill, and William D. S. Killgore. 2019. Increases in emotional intelligence after an online training program are associated with better decision-making on the Iowa gambling task. Psychological Reports 122: 853-79. [CrossRef] [PubMed]

Alvarado, Katherine A., Donald I. Templer, Charles Bresler, and Shan Thomas-Dobson. 1995. The relationship of religious variables to death depression and death anxiety. Journal of Clinical Psychology 51: 202-4. [CrossRef]

Allport, Gordon W., and James M. Ross. 1967. Personal religious orientation and prejudice. Journal of Personality and Social Psychology 5: 432-43. [CrossRef] [PubMed]

American Psychiatric Association. 2013. Diagnostic and Statistical Manual of Mental Disorders, 5th ed. Washington, DC: American Psychiatric Association.

Antonowski, Aaron. 1979. Health, Stress and Coping. San Francisco: Jossey-Bass.

Ardelt, Monika, and Cynthia S. Koenig. 2006. The role of religion for hospice patients and relatively healthy older adults. Research on Aging 28: 184-215. [CrossRef]

Arksey, Hilary, and Lisa O'Malley. 2005. Scoping studies: Towards a methodological framework. International Journal Social Research Methodology, Theory and Practice 8: 19-32. [CrossRef]

Arrowood, Robert Britton, Cathy R. Cox, Maddie Weinstock, and Jill Hoffman. 2018. Intrinsic religiosity protects believers from the existential fear of a human Jesus. Mental Health, Religion and Culture 21: 534-45. [CrossRef]

Bahrami, Nasim, Mohammad Moradi, Mohammad Soleimani, Zahra Kalantari, and Faeghe Hosseini. 2013. Death anxiety and its relationship with quality of life in women with cancer. Iran Journal of Nursing 26: 51-61.

Bakan, Ayse Berivan, Senay Karadag Arli, and Metin Ylldız. 2019. Relationship Between Religious Orientation and Death Anxiety in Elderly Individuals. Journal of Religion and Health 58: 2241-50. [CrossRef] 
Barnett, Michael D., Ellen A. Anderson, and Arthur D. Marsden III. 2018. Is death anxiety more closely linked with optimism or pessimism among older adults? Archives of Gerontology and Geriatrics 77: 169-73. [CrossRef]

Becker, Ernest. 1973. The Denial of Death. New York: Free Press.

Bridges, Ledetra, and Manoj Sharma. 2017. The Efficacy of Yoga as a Form of Treatment for Depression. Journal of Evidence-Based Complementary \& Alternative Medicine 22: 1017-28. [CrossRef]

Belsky, Janet. 1999. The Psychology of Aging: Theory, Research, and Interventions, 3rd ed. Pacific Grove: Brooks/Cole.

Britten, Nicky, Rona Campbell, Catherine Pope, Jenny Donovan, Myfanwy Morgan, and Roisin Pill. 2002. Using meta ethnography to synthesize qualitative research: A worked example. Journal of Health Services Research E Policy 7: 209-15.

Chan, Li Chuin, and Chin Choo Yap. 2009. Age, gender, and religiosity as related to death anxiety. Sunway Academic Journal 6: 1-16.

Cohen, Adam B., John D. Pierce Jr., Jacqueline Chambers, Rachel Meade, Benjamin J. Gorvine, and Harold G. Koenig. 2005. Intrinsic and extrinsic religiosity, belief in the afterlife, death anxiety, and life satisfaction in young Catholics and Protestants. Journal of Research in Personality 39: 307-24. [CrossRef]

Cornish, Marilyn A., and Nathaniel G. Wade. 2010. Spirituality and religion in group counseling: A literature review with practice guidelines. Professional Psychology: Research and Practice 41: 398. [CrossRef]

Dadfar, Mahboubeh, and David Lester. 2020. Death distress constructs A preliminary empirical examination of the Farsi form in nurses: A brief note. Nursing Open 7: 1026-31. [CrossRef]

Dadfar, Mahboubeh, David Lester, and Fazel Bahrami. 2016. Death anxiety, reliability, validity, and factorial structure of the Farsi form of the Arabic scale of death anxiety in Iranian old-aged persons. Journal of Aging Research 2016: 2906857. [CrossRef]

Dadfar, Mahboubeh, and D. Lester. 2017. Religiously, spirituality and death anxiety. Austin Journal of Psychiatry and Behavioral Sciences 4: 1061.

Dein, Simon. 2013. Religion, spirituality, depression, and anxiety: Theory, research, and practice. In APA Handbook of Psychology, Religion, and Spirituality: Vol. 2. An Applied Psychology of Religion and Spirituality. Edited by Kenneth I. Pargament, Annette Mahoney and Edward P. Shafranske. Washington, DC: American Psychological Association, pp. 241-55. [CrossRef]

Donahue, Michael J. 1985. Intrinsic and extrinsic religiousness: Review and meta-analysis. Journal of Personality and Social Psychology 48: 400-19. [CrossRef]

Donovan, James M. 1994. Defining Religion: Death and Anxiety in an Afro-Brazilian Cult. Unpublished Doctoral Dissertation, Tulane University, New Orleans, LA, USA.

Ellis, Lee, Eshan A. Wahab, and Malini Ratnasingan. 2013. Religiosity and fear of death: A three-nation comparison: Corrigendum. Mental Health, Religion \& Culture 16: 662.

Ens, Carla, and John B. Bond Jr. 2007. Death anxiety in adolescents: The contributions of bereavement and religiosity. Omega 55: 169-84. [CrossRef]

Farley, Graham. 2004. Death anxiety and death education: A brief analysis of the key issues. In Delivering Cancer and Palliative Care Education. Edited by Foyle Lorna and Hostad Janis. Oxford: Radcliffe, p. 229.

Finch, Emma C., Lisa Iverach, Ross G. Menzies, and Mark Jones. 2016. Terror mismanagement: Evidence that mortality salience exacerbates attentional bias in social anxiety. Cognition and Emotion 30: 1370-79. [CrossRef]

Florian, Victor, and Mario Mikulincer. 1998. Symbolic immortality and the management of the terror of death: The moderating role of attachment style. Journal of Personality and Social Psychology 74: 725. [CrossRef] [PubMed]

Frankl, Viktor E. 1963. Man's Search for Meaning. Boston: Beacon Press.

Galek, Kathleen, Neal Krause, Christopher G. Ellison, Taryn Kudler, and Kevin J. Flannelly. 2007. Religious doubt and mental health across the lifespan. Journal of Adult Development 14: 16-25. [CrossRef]

Gilliland, Jack C., and Donald I. Templer. 1986. Relationship of death anxiety scale factors to subjective states. Omega 16: 155-67. [CrossRef]

Harding, Stephen R., Kevin J. Flannelly, Andrew J. Weaver, and Karen G. Costa. 2005. The influence of religion on death anxiety and death acceptance. Mental Health, Religion and Culture 8: 253-61. [CrossRef]

Hart, Joshua, and Jamie L. Goldenberg. 2008. A terror management perspective on spirituality and the problem of the body. In Existential and Spiritual Issues in Death Attitudes. Edited by Adrian Tomer, Grafton T. Eliason and Paul T. P. Wong. New York: Lawrence Erlbaum, pp. 91-113.

Higgins, E. Tory. 1987. Self-discrepancy: A theory relating self and affect. Psychological Review 94: 319-40. [CrossRef]

Hodge, David R. 2013. Assessing spirituality and religion in the context of counselling and psychotherapy. In APA Handbook of Psychology, Religion, and Spirituality: Vol. 2. An Applied Psychology of Religion and Spirituality. Edited by Kenneth I. Pargament, Annette Mahoney and Edward P. Shafranske. Washington, DC: American Psychological Association, pp. 93-123. [CrossRef]

Hoelter, Jon W., and Janice A. Hoelter. 1978. The relationship between fear of death and anxiety. The Journal of Psychology: Interdisciplinary and Applied 99: 225-26. [CrossRef]

Hossain, Mohammad Samir, and Peter Gilbert. 2010. Concepts of death: A key to our adjustment. Illness Crisis E Loss 18: 19-36. [CrossRef]

Hui, Victoria Ka-Ying, and Helene H. Fung. 2008. Mortality anxiety as a function of intrinsic religiosity and perceived purpose in life. Death Studies 33: 30-50. [CrossRef]

Iverach, Lisa, Ross G. Menzies, and Rachel E. Menzies. 2014. Death anxiety and its role in psychopathology: Reviewing the status of a transdiagnostic construct. Clinical Psychology Review 34: 580-93. [CrossRef] 
Jafari, Simon. 2016. Religion and spirituality within counselling/clinical psychology training programmes: A systematic review. British Journal of Guidance \& Counselling 44: 257-67.

Jong, Jonathan, Robert Ross, Tristan Philip, Si-Hua Chang, Naomi Simons, and Jamin Halberstadt. 2018. The religious correlates of death anxiety: A systematic review and meta-analysis. Religion, Brain E Behavior 8: 4-20. [CrossRef]

Juhl, Jacob, Clay Routledge, Jamie Arndt, Constantine Sedikides, and Tim Wildschut. 2010. Fighting the future with the past: Nostalgia buffers existential threat. Journal of Research in Personality 44: 309-14. [CrossRef]

Kahoe, Richard D., and Rebecca Fox Dunn. 1975. The fear of death and religious attitudes and behavior. Journal for the Scientific Study of the Religion 14: 379-82. [CrossRef]

Kalish, Richard A. 1985. The social context of death and dying. In Handbook of Aging and the Social Sciences. Edited by R. H. Binstock and E. Shanas. New York: Van Nostrand Reinhold, pp. 149-70.

Kastenbaum, Robert, ed. 2000. The Psychology of Death, 3rd ed. New York: Springer.

Kelly, George A. 1955. The Psychology of Personal Constructs. vol. 1. A theory of personality. vol. 2. Clinical diagnosis and psychotherapy. New York: W. W. Norton.

Koenig, Harold G. 2012. Religion, spirituality, and health: The research and clinical implications. ISRN Psychiatry 2012: 278730. [CrossRef] [PubMed]

Lachal, Jonathan, Anne Revah-Levy, Massimiliano Orri, and Marie Rose Moro. 2017. Metasynthesis: An original method to synthesize qualitative literature in psychiatry. Frontiers in Psychiatry 8: 269. [CrossRef] [PubMed]

Langs, Robert. 2004. Death anxiety and the emotion-processing mind. Psychoanalytic Psychology 21: 31-53. [CrossRef]

Leming, Michael R., and George E. Dickinson. 2000. Understanding Dying, Death and Bereavement. In Death and Dignity. Edited by K. Hegedûs. Budapest: Osiris. (In Hungarian)

Le Marne, Kristina M., and Lynne M. Harris. 2016. Death anxiety, perfectionism and disordered eating. Behaviour Change 33: $193-211$. [CrossRef]

Lehto, Rebecca, and Karen Stein. 2009. Death Anxiety: An Analysis of an Evolving Concept. New York: Springer Publishing Company.

Lester, David. 1994. The Collett-Lester Fear of Death Scale. In Death Anxiety Handbook: Research, Instrumentation, and Application. Edited by Robert A. Neimeyer. Washington, DC: Taylor \& Francis, pp. 45-60.

Lester, David, Donald I. Templer, and Ahmed Abdel-Khalek. 2007. A cross-cultural comparison of death anxiety: A brief note. OMEGA-Journal of Death and Dying 54: 255-60. [CrossRef]

Lewis, Adam M. 2014. Terror management theory applied clinically: Implications for existential-integrative psychotherapy. Death Studies 38: 412-17. [CrossRef]

Li, Manyu, Vaishali Sameer Mardhekar, and Andre R. Rodriquez. 2017. Cross-cultural study of death anxiety in late adolescents. Adolescent Medicine and Health Care 1: 7-13.

Lonetto, Richard, and Donald I. Templer. 1986. Death Anxiety. Washington, DC: Hemisphere Publishing Corp.

Maddi, Salvatore R. 1970. The search for meaning. In Nebraska Symposium of Motivation. Edited by William J. Arnold and Monte M. Page. Lincoln: University of Nebraska Press, pp. 137-86.

Madnawat, A. V. Singh, and P. Singh Kachhawa. 2007. Age, gender, and living circumstances: Discriminating older adults on death anxiety. Death Studies 31: 763-69. [CrossRef]

Mahabeer, M., and K. Bhana. 1984. The relationship between religion, religiosity and death anxiety among Indian adolescents. South African Journal of Psychology 14: 7-9. [CrossRef]

Maheshwari, Saurabh, and Tuheena Mukherjee. 2019. Role of social detachment in coping with death anxiety: A case of elderly Hindu pilgrims. OMEGA-Journal of Death and Dying 79: 191-217. [CrossRef] [PubMed]

Malinauskaite, Ieva, Rimvydas Slapikas, Delphine Courvoisier, François Mach, and Baris Gencer. 2017. The fear of dying and occurrence of posttraumatic stress symptoms after an acute coronary syndrome: A prospective observational study. Journal of Health Psychology 22: 208-17. [CrossRef] [PubMed]

Marin, Samantha. 2019. The Relationship between Religiosity and Implicit vs. Explicit DEATH Anxiety. Honors dissertation for the degree of Bachelor of Science, Union College, Schenectady, NY, USA, p. 2324. Available online: https://digitalworks.union.edu/ theses / 2324 (accessed on 28 November 2020).

Maximo, Sally I. 2019. A Scoping Review of Ethical Considerations in Spiritual/Religious Counseling and Psychotherapy. Journal of Pastoral Care E Counseling 73: 124-33.

Menzies, Rachel E., and Ilan Dar-Nimrod. 2017. Death anxiety and its relationship with obsessive-compulsive disorder. Journal of Abnormal Psychology 126: 367-77. [CrossRef]

Menzies, Rachel E., and Ross G. Menzies. 2020. Death anxiety in the time of COVID-19: Theoretical explanations and clinical implications. The Cognitive Behaviour Therapist 13: e19. [CrossRef]

Menzies, Rachel E., Matteo Zuccala, Louise Sharpe, and Ilan Dar-Nimrod. 2018. The effects of psychosocial interventions on death anxiety: A meta-analysis and systematic review of randomised controlled trials. Journal of Anxiety Disorders 59: 64-73. [CrossRef]

Menzies, Rachel E., Louise Sharpe, and Ilan Dar-Nimrod. 2019. The relationship between death anxiety and severity of mental illnesses. British Journal of Clinical Psychology 58: 452-67. [CrossRef]

Michael, Scott T., and C. R. Snyder. 2005. Getting unstuck: The roles of hopes, finding meaning, and rumination in the adjustment to bereavement among college students. Death Studies 29: 435-58. [CrossRef] 
Mohammadzadeh, Ali, and Mahmoud Najafi. 2020. The comparison of death anxiety, obsession, and depression between Muslim population with positive and negative religious coping. Journal of Religion and Health 59: 1055-64. [CrossRef]

Moore, Calvin Conzelus, and John B. Williamson. 2003. The universal fear of death and the cultural response. In Handbook of Death $\mathcal{E}$ Dying. New York: SAGE Publications, pp. 3-13. [CrossRef]

Moore, Gavin. 2013. The Relationship between Religious Orientation, Coping Style, and Psychological Health on Death Anxiety and Life Satisfaction. Dublin: Dublin Business School.

Neimeyer, Robert A., and Kenneth M. Chapman. 1980. Selfhdeal discrepancy and fear of death: Testing an existential hypothesis. OMEGA-Journal of Death and Dying 11: 233-40. [CrossRef]

Ongider, N., and S. O. Eyuboglu. 2013. Investigation of death anxiety among depressive patients. Journal of Clinical Psychiatry 16: 34-46.

Pargament, Kenneth I., and Stephen M. Saunders. 2007. Introduction to the special issue on spirituality and psychotherapy. Journal of Clinical Psychology 63: 903-7. [CrossRef] [PubMed]

Pargament, Kenneth I., James W. Lomax, Jocelyn Shealy McGee, and Qijuan Fang. 2014. Sacred moments in psychotherapy from the perspectives of mental health providers and clients; Prevalence, predictors, and consequences. Spirituality in Clinical Practice 1: 248-62. [CrossRef]

Park, Hee Sun, Timothy R. Levine, Rene Weber, Hye Eun Lee, Lucia I. Terra, Isabel C. Botero, Elena Bessarabova, Xiaowen Guan, Sachiyo M. Shearman, and Marc Stewart Wilson. 2012. Individual and cultural variations in direct communication style. International Journal of Intercultural Relations 36: 179-87. [CrossRef]

Rogers, Carl Ransom. 1980. A Way of Being. Boston: Houghton-Mifflin.

Ross, J., G. Kennedy, and Francis Macnab. 2015. The Effectiveness of Spiritual/Religious Interventions in Pscychotherapy and Counselling: A Review of the Recent Literature. Melbourne: Psychotherapy and Counselling Federation of Australia (PACFA), pp. 1-23. Available online: https:/ /www.pacfa.org.au/wp-content/uploads/2012/10/Spiritual-and-Religious-Therapy-Literature-Review.pdf (accessed on 20 November 2020).

Saini, Prabhjot, Anurag B. Patidar, Ravneet Kaur, Mandeep Kaur, and Jasbir Kaur. 2016. Death anxiety and its associated factors among elderly population of Ludhiana city, Punjab. Indian Journal of Gerontology 30: 101-10.

Saleem, Tamkeen, and Shemaila Saleem. 2020. Religiosity and death anxiety: A study of Muslim dars attendees. Journal of Religion and Health 59: 309-17. [CrossRef]

Sherman, Deborah Witt, Robert Norman, and Christina Beyer McSherry. 2010. A comparison of death anxiety and quality of life of patients with advanced cancer or AIDS and their family caregivers. Journal of the Association of Nurses in AIDS Care 21: 99-112. [CrossRef]

Solomon, Sheldon, Jeff Greenberg, and Tom Pyszczynski. 2015. The Worm at the Core: On the Role of Death in Life. New York: Random House.

Sperry, Len. 2012. Spiritually sensitive psychotherapy: An impending paradigm shift in theory and practice. In The Oxford Handbook of Psychology and Spirituality. Edited by Lisa J. Miller. New York: Oxford University Press, pp. 223-36.

Strachan, Eric, Jeff Schimel, Jamie Arndt, Todd Williams, Sheldon Solomon, Tom Pyszczynski, and Jeff Greenberg. 2007. Terror mismanagement: Evidence that mortality salience exacerbates phobic and compulsive behaviours. Personality and Social Psychology Bulletin 33: 1137-51. [CrossRef]

Sullivan, Walter J. 1977. Effect of religious orientation, purpose in life, and locus of control on the death anxiety of college students. Unpublished doctoral dissertation, Dissertation Abstracts International 38: 382.

Taghiabadi, Mina, Ali Kavosi, Seyed Reza Mirhafez, Mahrokh Keshvari, and Tayebe Mehrabi. 2017. The association between death anxiety with spiritual experiences and life satisfaction in elderly people. Electronic Physician 9: 3980. [CrossRef] [PubMed]

Taylor, Shelley E. 1983. Adjustment to threatening events: A theory of cognitive adaptation. American Psychologist 38: 1161-73. [CrossRef]

Taylor, Shelley E., and Jonathon D. Brown. 1988. Illusions and well-being: A social psychological perspective on mental health. Psychological Bulletin 103: 193-210. [CrossRef] [PubMed]

Taylor, Shelley E., Rebecca L. Collins, Laurie A. Skokan, and Lisa G. Aspinwall. 1989. Maintaining positive illusions in the face of negative information: Getting the facts without letting them to get you. Journal of Social and Clinical Psychology 8: 114-29. [CrossRef]

Templer, Donald I. 1972. Death anxiety in religiously very involved persons. Psychological Reports 31: 361-62.

Templer, Donald I. 1976. Two factor theory of death anxiety: A note. Essence: Issues in the Study of Ageing, Dying, and Death 1: 91-93.

Tomer, Adrian, and Grafton Eliason. 1996. Toward a comprehensive model of death anxiety. Death Studies 20: 343-65. [CrossRef]

Varambally, Shivarama, and B. N. Gangadhar. 2020. Yoga and Traditional Healing Methods in Mental Health. Mental Health and Illness in the Rural World, 297-326. [CrossRef]

Viftrup, Dorte Toudal, Niels Christian Hvidt, and Niels Buus. 2013. Spiritually and religiously integrated group psychotherapy: A systematic literature review. Evidence-Based Complementary and Alternative Medicine, 274625. [CrossRef]

Willis, Kelcie D., Tamara Nelson, and Oswaldo Moreno. 2019. Death Anxiety, Religious Doubt, and Depressive Symptoms across Race in Older Adults. International Journal of Environmental Research and Public Health 16: 3645. [CrossRef]

Wen, Y. H. 2010. Religiosity and death anxiety. Journal of Human Resource and Adult Learning 6: 31-37. 
Wong, Paul T. P. 2008. Meaning management theory and death acceptance. In Death Attitudes: Existential E Spiritual Issues. Edited by A. Tomer, E. Grafton and P. T. P. Wong. Mahwah: Erlbaum.

Zhang, Jiaxi, Jiaxi Peng, Pan Gao, He Huang, Yunfei Cao, Lulu Zheng, and Danmin Miao. 2019. Relationship between meaning in life and death anxiety in the elderly: Self-esteem as a mediator. BMC Geriatrics 19: 308. [CrossRef] 